and would suggest that such a method can only be safely employed by a skilled ophthalmic surgeon. Occupational affections of the skin by Dr. Brown, of Boston, considered from the point of view of the various trades and callings, shows the variety of occupations which produce skin affections, and deals with such widely different occupations as housemaids, musicians, and surgeons. An attempt to include all who are likely to be affected by skin diseases has, we think, tended to crowd out some workers in the more important industries where such diseases in acute and severe forms are commonly met with. Little or no mention is made of dermatitis affecting workers in the nitroderivatives of benzol or toluol. A chapter on cancer and occupation is of interest, and includes effects produced by exposure to $X$ rays and radium. Part of this chapter is occupied with a brief description of the theories as to the causation of cancer, contagion and house infection, \&c. We hardly think such a study comes within the scope of the work.

Part II. deals with the Etiology and Prophylaxis of Occupational Diseases and Vocational Hygiene. Dr. Kober, one of the editors, contributes largely to this part. Much of his contribution is in the nature of a résumé on personal hygiene, and again we have a protest to utter against redundancy. We do not in any way minimise the value of personal hygiene in the prevention of occupational disease, but the omission of a consideration of this subject on general lines would in no way diminish the value of the essay. The subsequent sections of this part deal with the various industries and industrial poisonings, and special accidents attaching to them. Much of this is in many instances a repetition of Part 1 . Some contributors briefly outline the various processes of manufacture in which industrial poisoning is to be met. A few deal with the special preventive measures applicable to the various industries. We notice the brief reference to poisoning by trinitrotoluene and tetrachlorethane. In view of the importance which poisoning by these substances has assumed, we feel sure the subject will be more fully dealt with in future editions. One section is devoted to the subject of vocational hygiene of the liberal professions, public service employees. Several tables, one giving a list of industries and the poisons likely to be met with in each, and a series of mortality and morbidity statistics complete Part II.

Part III., the Relation of Hospital and Medical School Work, Statistics, Government Study and Legislation to Occupational Diseases, includes an interesting chapter by Professor L. Devoto, of Milan, in which he describes the Milan Clinic for Occupational Diseases. This should be read by all interested in occupational diseases and should orove an incentive to other countries to follow the lead given by Italy. Frederick L. Hoffmann, LL.D., contributes a chapter on the mortality from pulmonary tuberculosis and dusty occupations. The value of this chapter is diminished by the absence of a more definite analysis of the various dusts dealt with, but it contains a valuable lesson by showing the high rate of mortality from pulmonary tuberculosis among workers in dusty industries. A chapter on the use and the fallacies of statistics may be of interest and serve as a preliminary study to those who have no knowledge of the subject but who wish to take an intelligent interest therein. The remainder of Part III. is concerned with legislative measures and the notification of occupational diseases.

We congratulate the editors on the result of their work, which is well illustrated throughout.

Text.book of Ophthalmology. By Hofrat ERNst FucHs, Professor of Ophthalmology in the University of Vienna, Authorised translation by ALExander DuANE, M.D. Surgeon Fmeritus, Knapp Memorial Hospital, New York. Fifth edition. London and Philadelphia: J. B. Lippincott Company. 1917. Pp. 1067. Price 30s.

IN previous reviews of this work we have always expressed the opinion that it is the best of the larger text-books of ophthalmology. In the presence of several excellent competitors it can only retain this proud position by keeping well abreast of the times. The new (fifth) edition not only sustains but enhances its high reputation. Though Dr. Duane is very careful to distinguish his additions to the original by the use of square brackets, they are so ubiquitous that it is difficult to apportion the author's and the translator's contributions. A rough estimate indicates that the latter is responsible for nearly half the book. In previous editions the joins in the mosaic have been very evident. In this edition, in spite of the brackets, the welding is very much more satisfactory. Another great improvement consists in changes in the arrangement of the original text. The many pages of remarks in fine print, which were formerly massed as an appendix at the end of chapters or major divisions, and whose considerable value and interest were thus obscured, have been split into shorter sections, each placed in direct juxtaposition to the portion of the text to which it relates. Considerable additions have been made to the chapters on glaucoma, diseases of the retina, and disturbances of motility, and to the sections on refraction, accommodation, and operations. Dr. Duane's well-known interest in ocular paralyses is given perhaps rather too free play, somewhat to the detriment of proper balance. On the other hand, some of the chapters on operations might be still further elaborated with advan. tage. Other important additions deal with tuberculin and vaccine therapy, the visual field and colour testing, the mapping of scotomata and the blind spot, the etiology of iritis, suppurative choroiditis, retinitis exudativa, and so on.

The book is an admirable exposition of the subject and is well adapted for advanced students. We think, however, that it has reached the limit of size suitable for a text-book. Any further additions should be thoroughly incorporated, and room should be made for them by careful compression of the existing text.

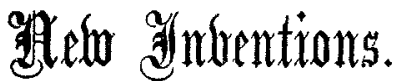

\section{A PNHUMATIC TOURNIQUET FOR AMPUTATIONS AND OTHER PURPOSES.}

Several years ago I had made a pneumatic tourniquet resembling the one used by Mr. R. H. Jocelyn Swan for intravenous injections. In this case, however, the tourniquet is adapted for use in amputations and in the arrest of severe bæmorrhage from the limbs. It has the two additional advantages that it is easily sterilised and can be easily controlled by an anæsthetist standing at the head of the patient. The tourniquet consists of a rubber bag two inches wide and some 20 inches in length (for use with adults). Halfway along one edge of the bag is inserted the inlet tube T-fashion. The inlet tube is 4 feet long and ends in a stout bulb. The bulb is fitted with a valve, as in the Riva-Rocci apparatus, and a simple spring clip. The

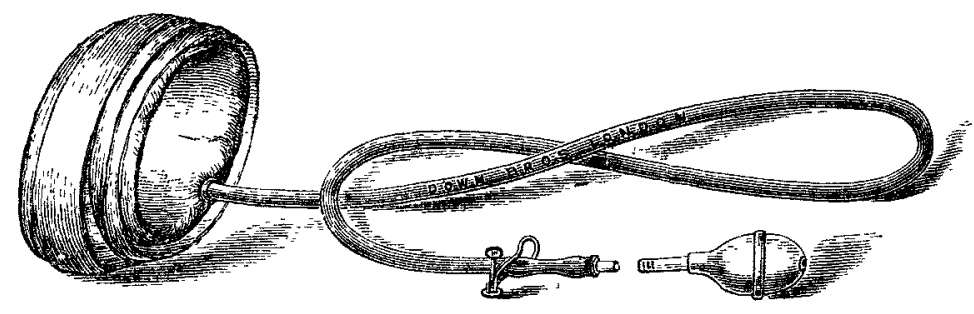

bag is fitted in a sterilisable cover and has a lead back to prevent rolling when distended, this improvement being originally suggested by Colonel A. Fullerton. In use the bag is wrapped round the limb, the inlet tube passing towards the head. A $2 \frac{1}{2}$-inch linen bandage is then firmly applied over the tourniquet and the bag inflated till the distal pulse disappears. In the course of an amputation. when all bleeding points have been secured the anæsthetist, by manipulating the valve-end, can release the pressure, pumping up again if bleeding recommences. In operating on patients with brittle arteries less damage will be done by this tourniquet than by any other, because the pressure is only just sufficient to compress the artery, and can be released immediately the artery is tied. This tourniquet should prove useful in the transport of wounded when there is fear of hæmorrhage. The bag and bandage can be applied beforehand, the actual inflation being all that is required if the emergency arises. In this case one inflates till the bleeding stops, a proceeding which conld be left to a comparatively inexperienced person.

The makers are Messrs. Down Brothers, of St. Thomas'sstreet, London, S.E.

J. V. FIDDraN, Captain, R.A.M.C 


\section{THE LANCET.}

LONDON : SATURDAY, OCTOBER $27,191 \%$.

\section{The Position of Practice under the National Insurance Act.}

A CONFERFNCE of Representatives of Local Nedical and Panel Committees of Great Britain was held in London on Oct. 18th under the anspices of the British Medical Association. A year had gone by since the last Conference, and some of the points at issue then were found to have been cleared up, while the focus of interest has shifted in regard to others. The perennial difficulty in grasping the working of the "central pool" has remained in spite of the persuasive memorandum issued by the Insurance Commissioners, and the recent Conference decided without hesitation to ask the Commissioners to allow six representatives of the Insurance Acts Committee of the British Medical Association to assure themselves, with the aid of an actuary, that all the money received on account of medical benefit did really find its way into the medical practitioners' pockets. In this connexion the existence of "inflation" of the panel list and its effect on medical accounts was fully recognised, being understood more readily in view of the growing familiarity with the process in other departments of life. Admittedly there is less inflation in the case of munition centres than in other areas, but no action was taken in the direction of pressing for preferential treatment of panel practice in urban areas. The Conference was unanimous in wishing to be assured that the total pool was correct, but was not squeamish about its distribution. On the contrary, a keen sympathy was expressed with the difficulties of the rural practitioner, which are at their greatest in Scotland (cf. p. 656). During the year a Rural Practice Subcommittee has been at work considering the special hardships of rural panel practice. Two of these hardships have been sadly accentuated during the past 12 months. The discharged service man in the country cannot attend personally at his doctor's dispensary, but must be visited, it may be at a great distance. The cost of petrol has gone up by leaps and bounds without corresponding increase in the mileage allowance. The rural practitioner's time is as valuable as that of his colleagues, and whether or no the mileage allowance covers the out-of-pocket expenses of his journeys, he has at all events to bear unrequited the expenditure of time involved.

The Conference confirmed by an overpowering majority the decision of the Insurance Acts Committee of the British Medical Association in regard to the payment for attendance on the disabled service man by visit instead of on a capitation basis. In so doing there was apparently no intention of reversing the doctrine that the capitation fee is the ideal system for medical treatment of an insured population. Under whatever other treatment-specialist, training, re-educational - the disabled man comes, the capitation fee, if it does nothing else, ensures his surveillance by his own family doctor. The arrangement was regarded by the Conference, as by the Insurance Acts Committee which made it, in the light of a temporary expedient in order to elucidate the question whether the disabled soldier is likely to be a more considerable charge on the practitioner's time and skill than his average panel patient. Since the decision was made, however, various factors have come in to complicate the situation. With some of these we deal on pp. 655-6. Treatment by general and V.A.D. hospitals of disabled men as out-patients, if it becomes the general policy of the Pensions Ministry, may result in taking this work so completely out of the hands of the practitioner that the fees earned per visit may work out, in fact, less than a capitation fee on the old lines, and this whatever may be the decision of the volun. tary staffs of hospitals in regard to their own remuneration. The principle of the capitation fee was, indeed, vindicated by the unanimous vote of the Conference to empower the Insurance Acts Committee to press for an increase of the capitation fee to a sum of $10 \mathrm{~s}$. per insured person, this sum to cover increased liabilities in regard to dis. charged sailors and soldiers, as well as all services now rendered to tuberculous patients by panel doctors. The steadily increasing cost of living and of carrying on practice makes this decision a logical one, in spite of the attitude taken up a year ago not to press the matter on patriotic grounds. The increased cost to the Insurance Commissioners of raising the capitation fee was stated to be about half a million pounds, the increase implying a rise of 43 per cent. on the panel practitioner's present income, or an addition of $£ 3$ per week on a panel of 1000. It is to be hoped that this rise may equitably solve even the difficulties of the rural practitioner in regard to mileage and petrol.

The scheme for collective bargaining drawn up by the Insurance Acts Committee of the British Medical Association, as well as its application of the principle during the past twelvemonth, met with the general approval of the Conference, although a small but vocal section expressed its dissatisfaction with the representation of its views by the Committee, not on personal grounds but on the basis of political expediency. It was argued that negotiations affecting the panel service should be carried on by direct representatives of the statutory panel committees, and that for this purpose an association of panel committees or a panel medicopolitical union would be more appropriate than a committee of the British Medical Association. This movement is an interesting one for a more stringent trades unionism within the medical profession at a time when the Labour Party itself has just taken the step of extending the basis of its representation, and it may not be unfair to compare the constitution of the British Medical Association with that of the reconstituted Labour Party. The 